\title{
Analysis and Anticancer Effects of Active Compounds from Spatholobi Caulis in Human Breast Cancer Cells
}

\author{
Hung Manh Phung ${ }^{1,+}+\mathbb{D}$, Hesol Lee ${ }^{2,+}$, Sullim Lee ${ }^{3,+}{ }^{\oplus}$, Dongyeop Jang ${ }^{4}$, Chang-Eop Kim ${ }^{4}(\mathbb{D}$, \\ Ki Sung Kang ${ }^{1}$, Chang-Seob Seo ${ }^{5, * 10}$ and You-Kyung Choi ${ }^{2, *}$ \\ 1 Department of Preventive medicine, College of Korean Medicine, Gachon University, \\ Seongnam 13120, Korea; manhspkt92@gmail.com (H.M.P.); kkang@gachon.ac.kr (K.S.K.) \\ 2 Department of Korean International Medicine, College of Korean Medicine, Gachon University, \\ Seongnam 13120, Korea; haesol89@naver.com \\ 3 Department of Life Science, College of Bio-Nano Technology, Gachon University, Seongnam 13120, Korea; \\ sullimlee@gachon.ac.kr \\ 4 Department of Physiology, College of Korean Medicine, Gachon University, Seongnam 13120, Korea; \\ jngdngyp@naver.com (D.J.); eopchang@gachon.ac.kr (C.-E.K.) \\ 5 Herbal Medicine Research Division, Korea Institute of Oriental Medicine, Daejeon 34054, Korea \\ * Correspondence: csseo0914@kiom.re.kr (C.-S.S.); kosmos@gachon.ac.kr (Y.-K.C.); \\ Tel.: +82-42-868-9361 (C.-S.S.); +82-32-770-1300 (Y.-K.C.) \\ + These authors contributed equally to this work.
}

Received: 21 July 2020; Accepted: 18 September 2020; Published: 21 September 2020

\begin{abstract}
Breast cancer is the most common malignancy in both developing and developed countries. In this study, we simultaneously analyzed nine constituent compounds from Spatholobi Caulis (gallic acid, (-)-gallocatechin, 3,4-dihydroxybenzoic acid, procyanidin B1, 3,4-dihydroxybenzaldehyde, catechin, procyanidin B2, epicatechin, and (-)-epicatechin gallate) and examined their anticancer effects on MCF-7 and MDA-MB-231 human breast cancer cells. The experimental results indicated that the gallic acid showed the strongest cytotoxic effect on MCF-7 cells among tested compounds whilst most of samples did not express inhibitory effect on viability of MDA-MB-231 cells, except for $70 \%$ ethanol extract of $S$. Caulis. Thus, gallic acid was chosen to extend anticancer mechanism study on MCF-7 cells. Our data showed that the gallic acid induced apoptotic MCF-7 cell death through both extrinsic and intrinsic pathways, which increased the expression of cleaved caspase-7, -8 , and -9 , Bax and p53, but reduced the expression of Bcl-2 and poly (ADP-ribose) polymerase (PARP). In addition, the network pharmacological analysis pointed out that the p53, mitogen-activated protein kinase (MAPK), estrogen, and Wnt signaling pathways have a great correlation with the targets of gallic acid. This study suggested that gallic acid is a bioactive component of $S$. Caulis with potential to be used in chemotherapy for breast cancer.
\end{abstract}

Keywords: MCF-7; breast cancer; Spatholobi Caulis; gallic acid; apoptosis; p53; network pharmacology

\section{Introduction}

Globally, breast cancer is the most common female malignancy and the second-leading cause of cancer death in women following cancer of the lung and bronchus [1]. Systemic treatment (chemotherapy) and local therapy (radiotherapy and surgery) are the current typical treatments for breast cancer [2]. However, cytotoxic antineoplastic drugs or ionizing radiation generally result in side effects during treatment [3,4]. Thus, the search for new medicinal sources of compounds with high therapeutic effect and fewer adverse reactions is a key target of anticancer drug development.

The phytochemistry is well known as a nontoxic and abundant source of anticancer compounds [5]. In fact, more than 50\% of molecules approved between 1981 and 2014 were from natural sources, with 
the antitumor effects as their primary functionality [6]. The anticancer effect of herbs not only are widely studied in in vitro and in vivo models, but also were recorded in several clinical reports [7]. Taking a case study of a 77-year-old female patient with lung carcinoma as an example, Kamei et al. [8] indicated that Ninjin yoei To (traditional Chinese herb) reduced the levels tumor markers, namely CEA and CA19-9, from 14.6 to $11.3 \mathrm{ng} / \mathrm{mL}$ and 55 to $39.2 \mathrm{U} / \mathrm{mL}$, respectively.

Sun et al. [9] showed that plant-derived compounds can reverse, delay, or inhibit carcinogenesis by regulating multiple cell signaling pathways related to the formation and progression of tumors, such as invasion, angiogenesis, proliferation, metastasis, and apoptosis. Apoptosis plays key roles in tissue homeostasis and in the embryonic development of multicellular organisms through the regulation of typical cellular signals and other mechanisms. When these mechanisms and signals are disturbed by various factors, including mutations, loss of apoptosis may occur, resulting in uncontrolled cell proliferation, characteristic of cancer. Thus, reversing these signals is helpful for the mitigation of carcinogenesis [10].

Spatholobi Caulis (SC) is a traditional Chinese herb produced from the vine stem of Spatholobus suberectus Dunn and has been shown to have anti-inflammatory, anti-osteoarthritic, anti-anemic, antiviral, and neuroprotective effects [11-15]. Furthermore, the cytotoxicity of SC was reported on various cancerous cell lines, such as monocyte leukemia, cervical cancer, osteosarcoma cancer, and colorectal cancer [16-20]. Phenolic compounds, including flavanones, flavan-3-ol, chalcone, isoflavonoids, and phenolic acids, are considered the primary bioactive constituent compounds of SC [21,22] expressing anticancer activity against several cancer cell lines [23]. For example, (-)-epicatechin gallate, a flavanol in SC, induces apoptosis in colon, head, and neck carcinoma cells [24,25]. In addition, the anticancer effect of gallic acid found in SC was reported in lung and prostate cancer cells $[26,27]$. In this study, we simultaneously analyzed 9 marker components of SC $((-)$-gallocatechin, procyanidin B1, catechin, procyanidin B2, epicatechin, (-)-epicatechin gallate, gallic acid, 3,4-dihydroxybenzoic acid, and 3,4-dihydroxybenzaldehyde) (Figure 1) [19] and assessed their cytotoxicity in two human breast cancer cell lines including MCF-7 and MDA-MB-231 cells.
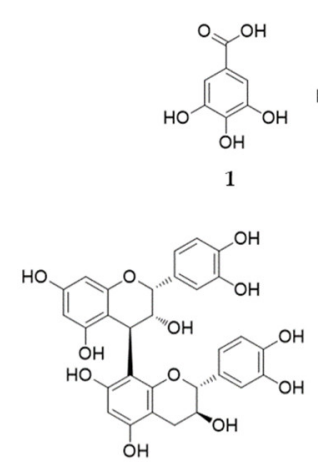

4

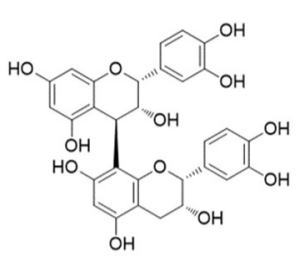

7
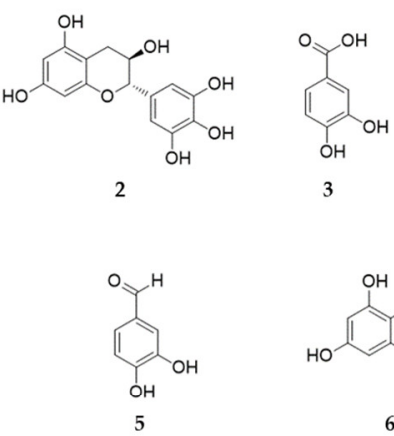

3
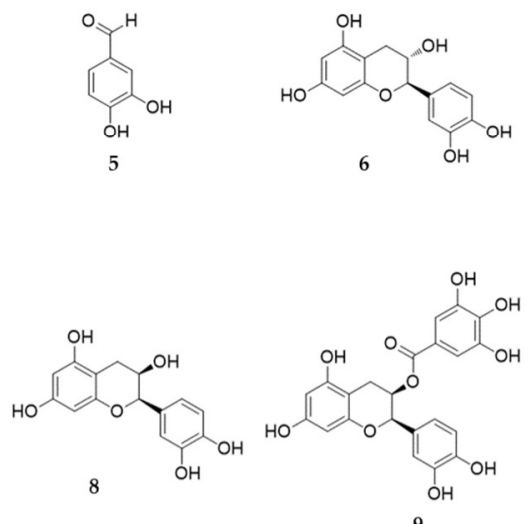

9

Figure 1. Nine marker compounds in Spatholobi Caulis (SC). Gallic acid (1), (-)-gallocatechin (2), 3,4-dihydroxybenzoic acid (3), procyanidin B1 (4), 3,4-dihydroxybenzaldehyde (5), catechin (6), procyanidin B2 (7), epicatechin (8), and (-)-epicatechin gallate (9). 


\section{Materials and Methods}

\subsection{Plant Material}

SC was purchased from Kwangmyungdag Medicinal Herbs (Ulsan, Korea). The plant material was authenticated by Dr. Goya Choi of the Herbal Medicine Resources Research Center, Kora Institute of Oriental Medicine (Naju, Korea). A voucher specimen (SC-2019) was deposited at the College of Korean Medicine, Gachon University (Seongnam, Korea).

\subsection{Chemicals and Reagents}

Nine reference standard compounds were purchased: gallic acid (purity $=97.5-102.5 \%$ ), $(-)$-gallocatechin (purity $=100.0 \%$ ), 3,4-dihydroxybenzaldehyde (purity $=97.0 \%$ ), and catechin (purity $=99.0 \%$ ) from Merck KGaA (Darmstadt, Germany);3,4-dihydroxybenzoic acid (purity = 98.0\%) from ChromaDex (Santa Ana, CA, USA); procyanidin B1 (purity = 97.8\%) and (-)-epicatechin gallate (purity $=98.7 \%$ ) from Shanghai Sunny Biotech Co., Ltd. (Shanghai, China); and procyanidin B2 (purity $=98.6 \%$ ) and epicatechin (purity $=99.3 \%$ ) from Biopurify Phytochemicals (Chengdu, China). High-performance liquid chromatography (HPLC)-grade solvents (water, methanol, and acetonitrile) was supplied from J. T. Baker (Phillipsburg, NJ, USA). ACS reagent-grade formic acid ( $\geq 98.0 \%)$ was purchased Merck KGaA (Darmstadt, Germany).

\subsection{Making 70\% Ethyl Alcohol Extract of Spatholobi Caulis Spatholobi Caulis}

A mass of $10.0 \mathrm{~kg}$ of dried herbal medicine SC was extracted with $100 \mathrm{~L}$ ethyl alcohol (70\%) for $180 \mathrm{~min}$ at $80^{\circ} \mathrm{C}$ by using a vacuum herb extractor (Cosmos 660, Kyungseo Machine, Incheon, Korea), and then concentrated to remove ethanol. The ethanol-free extract was lyophilized using an Ilshin BioBase PVTFD-100 freeze dryer (Dongducheon, Korea) to obtain 857.7 g powdered extract.

\subsection{High-Performance Liquid Chromatography Analysis of the Nine Marker Compounds in Spatholobi Caulis}

HPLC analysis of the nine marker compounds as a quality control measure for SC was performed by using a Shimadzu Prominence LC-20A Series (Kyoto, Japan) coupled photodiode array (PDA) detector and LabSolution software (Version 5.53, SP3, Kyoto, Japan) for data acquisition and processing. The 9 marker components were separated on Waters SunFire ${ }^{\mathrm{TM}} \mathrm{C}_{18}$ analytical column $(4.6 \times 250 \mathrm{~mm}$, $5 \mu \mathrm{m}$; Torrance, CA, USA) maintained at $30{ }^{\circ} \mathrm{C}$ and two mobile phases, which consisted of $0.1 \%(v / v)$ aqueous formic acid (A) and $0.1 \%(v / v)$ formic acid in acetonitrile. The following gradient elution profile was used: $0-40 \mathrm{~min}, 5-40 \% \mathrm{~B} ; 40-45 \mathrm{~min}, 40 \% \mathrm{~B} ; 45-50 \mathrm{~min}, 40-50 \% \mathrm{~B}$. The flow rate of the mobile phase was $0.8 \mathrm{~mL} / \mathrm{min}$, and the injected volume was $10 \mu \mathrm{L}$. For the simultaneous analysis of the nine marker compounds in SC (gallic acid, (-)-gallocatechin, 3,4-dihydroxybenzoic acid, procyanidin B1, 3,4-dihydroxybenzaldehyde, catechin, procyanidin B2, epicatechin, and (-)-epicatechin gallate), $0.2 \mathrm{~g}$ powdered extract of SC was dissolved in $20 \mathrm{~mL}$ methyl alcohol (70\%) and sonicated for $1 \mathrm{~h}$. The extracted solutions were filtered through a $0.2 \mu \mathrm{m}$ membrane filter (Pall Life Sciences, Ann Arbor, MI, USA) before injection into the HPLC system.

\subsection{Cell Culture and Drug Preparation}

The MDA-MB-231 and MCF-7 cells (ATCC, Manassas, VA, USA) were maintained and cultured in Roswell Park Memorial Institute medium (RPMI 1640; Corning, Manassas, VA, USA) supplemented with 10\% fetal bovine serum (FBS; Atlas, Fort Collins, CO, USA), $100 \mu \mathrm{g} / \mathrm{mL}$ streptomycin, and 100 units/mL penicillin (Gibco, Grand Island, NY, USA). The growth conditions were set at $37^{\circ} \mathrm{C}$, $5 \% \mathrm{CO}_{2}$ and $95 \%$ relative humidity. The stock solution of SC extract $(100 \mathrm{mg} / \mathrm{mL})$ and 9 compounds (100 mM) were prepared in dimethyl sulfoxide (DMSO; Santa Cruz Biotechnology, Dallas, TX, USA). A $1 \mathrm{mM}$ stock solution of cisplatin was made in autoclaved distilled water. The final percentage of 
DMSO was controlled less than $1 \%$, which showed no cytotoxicity on tested cell lines compared to non-treated cells.

\subsection{Cell Viability Assay}

Cell viability was assessed using the EZ-Cytox enhanced cell viability assay kit (Dogen, Daeil Lab Service, Seoul, Korea). The cells were seeded in 96-well plates at $1 \times 10^{4}$ cells/well and allowed to adhere for $24 \mathrm{~h}$. After treatment with the specified sample concentrations for $24 \mathrm{~h}, 10 \mu \mathrm{L}$ EZ-Cytox was added to each well and the plates were incubated at the growth conditions for $45 \mathrm{~min}$. The $\mathrm{OD}_{450}$ per well was measured by using an ELISA reader (Accuris SmartReader 96; Benchmark Scientific, Edison, NJ, USA), and cell viability was presented as a proportion relative to the survivability of non-treated cells.

\subsection{Nuclear Staining}

The condensation of nuclei was determined by using the method of Xia et al. [28] with slight modifications. After treatment with the indicated doses of each sample for $12 \mathrm{~h}$, the cells were dyed with 0.01 M Hoechst 33,258 (PromoKine, Heidelberg, Germany) for $10 \mathrm{~min}$ in shadow. Images of the cell nuclei were visualized by an IX51 fluorescence microscope (Olympus, Tokyo, Japan) connected with a CCD camera.

\subsection{Tali Assay}

The MCF-7 cells were treated with compounds at specific concentration in $12 \mathrm{~h}$. After that, the cells were harvested and dyed with PI and Annexin V (Tali ${ }^{\circledR}$ Apoptosis Kit, Thermo Fisher Scientific, Eugene, OR, USA) to detect dead and apoptotic cells using the Tali ${ }^{\circledR}$ Image-Based Cytometer (Invitrogen, Carlsbad, CA, USA). The portion of cells undergoing apoptosis was assessed using TaliPCApp, version 1.0.

\subsection{Western Blotting}

The western blotting analysis protocol of Jang et al. [29] with slight adjustments was applied to detect expression of proteins-modulated apoptosis. MCF-7 cells $\left(4 \times 10^{5}\right.$ cells/well) were seeded on 6-well plates and incubated for $24 \mathrm{~h}$ at $37^{\circ} \mathrm{C}$ in a humid atmosphere with $5 \% \mathrm{CO}_{2}$. The cells were treated with specific concentrations of each sample for $24 \mathrm{~h}$, harvested, lysed in $1 \times$ RIPA buffer (Rockland Immunochemicals, Pottstown, PA, USA) containing $2 \mathrm{mM}$ sodium orthovanadate (Santa Cruz Biotechnology, Dallas, TX, USA), 5 mM sodium fluoride (Sigma-Aldrich, St. Louis. MO, USA) and protease inhibitor cocktail (Roche Diagnostics, Indianapolis, USA), and centrifuged (16,000X $g$ at $4{ }^{\circ} \mathrm{C}$ for $20 \mathrm{~min}$ ) to collect the supernatant. The concentration of protein in the solutions was quantified using the Pierce ${ }^{\mathrm{TM}}$ BCA Protein Assay Kit (Thermo Fisher Scientific, Rockford, IL, USA). Equal amounts of protein were separated by sodium dodecyl sulfate-polyacrylamide gel electrophoresis (SDS-PAGE), and the separated proteins were transferred to polyvinylidene fluoride membranes (Bio-Rad Laboratories Inc., Hercules, CA, USA). Non-specific binding to the membranes was blocked by incubation in 5\% nonfat milk in Tris-buffered saline containing $0.1 \%$ Tween-20 (TBS-T) for $1 \mathrm{~h}$. Subsequently, the membranes were probed with the primary antibodies to cleaved caspase-9, cleaved caspase-8, cleaved caspase-7, Bax, B-cell lymphoma 2 (Bcl-2), p53, poly (ADP-ribose) polymerase (PARP) and glyceraldehyde 3-phosphate dehydrogenase (GAPDH), and with secondary antibodies (Santa Cruz Biotechnology, Dallas, TX, USA). After treatment membranes by ECL solution (Promega, Madison, WI, USA), the immunoblotting bands were developed using the ChemiDoc XRS+ System (Biorad, Hercules, CA, USA).

\subsection{Network Pharmacological Analyses}

For prediction of targets of gallic acid and determination of its relevant pathways, network pharmacological was assessed with potential targets obtained from STITCH (http://stitch.embl.de/) 
(Szklarczyk, Damian, et al. "STITCH 5: Augmenting protein-chemical interaction networks with tissue and affinity data." Nucleic acids research 44.D1 (2016): D380-D384.). Targets that had combined scores more than 700, which is set as a default threshold in STITCH, were selected. The performance of STITCH for the prediction of compound-target interactions has been shown to be reliable. (Kuhn et al. [30] "STITCH 4: Integration of protein-chemical interactions with user data." Nucleic acids research 42.D1 (2014): D401-D407.)

The gene set enrichment analysis (GSEA) relied on Enrichr (http://amp.pharm.mssm.edu/Enrichr/) (Kuleshov et al. [31] "Enrichr: a comprehensive gene set enrichment analysis web server 2016 update." Nucleic acids research 44.W1 (2016): W90-W97.) was applied to identify the pathways associated with the targets. Enrichr computes enrichment by the assessment of multiple gene-set libraries (e.g., Online Mendelian Inheritance in Man, Kyoto Encyclopedia of Genes and Genomes (KEGG), and gene ontology) and computed z-scores, adjusted $p$-values, and integrated scores for target genes. The logarithm of the multiplication of the z-score and the $p$-value was used to define the combined score.

A compound-target network is a bipartite network, in which nodes are defined as compounds and targets and the edges between compounds and targets are defined as compound-target interactions ( 1 or 0 ). We constructed compound-target network using above mentioned information about the compounds, targets, and pathways of gallic acid and visualized the network using Cytoscape (version 3.6.1) (Shannon, Paul, et al. "Cytoscape: A software environment for integrated models of biomolecular interaction networks." Genome research 13.11 (2003): 2498-2504.APA).

\subsection{Statistical Method}

The experimental data were expressed as the mean \pm SD. One-way analysis of variance (ANOVA) with Tukey's honest significance test was used to assess the significance of differences, with $p$-values of less than 0.05 considered statistically significant.

\section{Results and Discussion}

In the present study, the simultaneous analysis of nine analytes in SC (gallic acid, (-)-gallocatechin, 3,4-dihydroxybenzoic acid, procyanidin B1, 3,4-dihydroxybenzaldehyde, catechin, procyanidin B2, epicatechin, and (-)-epicatechin gallate) was conducted using the optimized HPLC-PDA method. All marker components for simultaneous analysis were eluted within $30 \mathrm{~min}$ with a resolution of $>1.6$ (Figure 2).

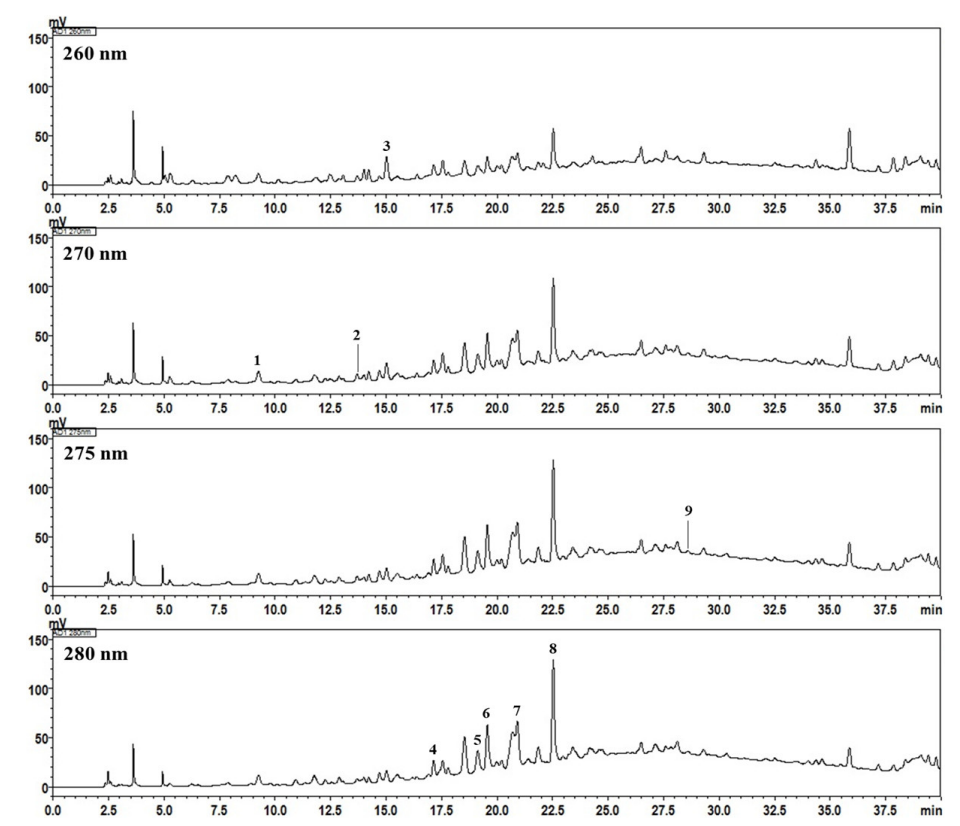

Figure 2. High-performance liquid chromatography (HPLC) chromatograms of the 70\% ethanol 
extract of Spatholobi Caulis (SC). Gallic acid (1), (-)-gallocatechin (2), 3,4-dihydroxybenzoic acid (3), procyanidin B1 (4), 3,4-dihydroxybenzaldehyde (5), catechin (6), procyanidin B2 (7), epicatechin (8), and (-)-epicatechin gallate $(9)$.

The quantification of these components was performed at $260 \mathrm{~nm}$ for 3,4-dihydroxybenzoic acid, $270 \mathrm{~nm}$ for gallic acid and (-)-gallocatechin, $275 \mathrm{~nm}$ for (-)-epicatechin gallate, and $280 \mathrm{~nm}$ for procyanidin B1, 3,4-dihydroxybenzaldehyde, catechin, procyanidin B2, and epicatechin, based on the $\lambda$ max of the UV spectrum. Calibration data, the coefficient of determination $\left(r^{2}\right)$, limit of detection (LOD), and limit of quantification (LOQ) are summarized in Table 1. The data showed good linearity, with an $r^{2}$ of $\geq 0.9996$ at the tested concentration levels. The concentrations of the nine marker compounds in the SC sample are shown in Table 2. The concentration of procyanidin B2 was expressed as a semi-quantitative value because it is not completely separated from the adjacent peak as shown in Figure 2.

Table 1. Linear range, regression equation, $r^{2}$, limit of detection (LOD), and limit of quantification (LOQ) for the nine marker compounds $(n=3)$.

\begin{tabular}{|c|c|c|c|c|c|c|}
\hline No & Compound & $\begin{array}{l}\text { Linear } \\
\text { Range } \\
(\mu \mathrm{g} / \mathrm{mL})\end{array}$ & $\begin{array}{l}\text { Regression Equation } \\
\quad(y=a x+b)^{a}\end{array}$ & $r^{2}$ & $\begin{array}{c}\text { LOD } \\
(\mu \mathrm{g} / \mathrm{mL})^{b}\end{array}$ & $\begin{array}{c}\text { LOQ } \\
(\mu \mathrm{g} / \mathrm{mL})^{c}\end{array}$ \\
\hline 1 & Gallic acid & $0.16-10.00$ & $y=51,544.39 x-3596.01$ & 0.9996 & 0.03 & 0.08 \\
\hline 2 & (-)-Gallocatechin & $0.78-50.00$ & $y=3788.85 x-539.68$ & 1.0000 & 0.23 & 0.71 \\
\hline 3 & 3,4-Dihydroxybenzoic acid & $0.16-10.00$ & $y=68,850.48 x-3189.43$ & 0.9999 & 0.03 & 0.08 \\
\hline 4 & Procyanidin B1 & $1.56-100.00$ & $y=8959.72 x-3750.11$ & 0.9999 & 0.26 & 0.78 \\
\hline 5 & 3,4-Dihydroxybenzaldehyde & $0.31-20.00$ & $y=116,002.12 x-10,175.98$ & 0.9999 & 0.02 & 0.07 \\
\hline 6 & $(+)$-Catechin & $1.56-100.00$ & $y=18,339.66 x-6373.92$ & 0.9999 & 0.19 & 0.58 \\
\hline 7 & Procyanidin B2 & $4.69-300.00$ & $y=8625.79 x-8476.36$ & 0.9999 & 0.72 & 2.19 \\
\hline 8 & Epicatechin & $4.69-300.00$ & $y=10,663.73 x-8145.46$ & 0.9999 & 0.57 & 1.72 \\
\hline 9 & (-)-Epicatechin gallate & $0.31-20.00$ & $y=25,065.19 x-3031.59$ & 0.9997 & 0.08 & 0.24 \\
\hline
\end{tabular}

${ }^{\mathrm{a}} y$ : peak area (mAU) of compounds; $x$ : concentration $(\mu \mathrm{g} / \mathrm{mL})$ of compounds; ${ }^{\mathrm{b}} \mathrm{LOD}=3.3 \times \sigma / S ;{ }^{\mathrm{c}} \mathrm{LOQ}=10 \times \sigma / S$, where $\sigma$ is the standard deviation of the $y$-intercept and each calibration curve $(\sigma)$, and $S$ is the slope of the calibration curve.

Table 2. Concentrations of the nine marker components in the SC sample determined by HPLC analysis $(n=3)$.

\begin{tabular}{ccccc}
\hline No & Compound & Mean $(\mathbf{m g} / \mathbf{g})$ & SD $\times \mathbf{1 0}^{-\mathbf{2}}$ & RSD (\%) \\
\hline 1 & Gallic acid & 0.32 & 0.63 & 1.97 \\
2 & (-)-Gallocatechin & 3.40 & 6.19 & 1.82 \\
3 & 3,4-Dihydroxybenzoic acid & 0.43 & 0.56 & 1.31 \\
4 & Procyanidin B1 & 1.63 & 0.86 & 0.53 \\
5 & 3,4-Dihydroxybenzaldehyde & 0.23 & 0.06 & 0.27 \\
6 & (+)-Catechin & 2.57 & 0.75 & 0.29 \\
7 & Procyanidin B2 & 5.69 a & 4.31 & 0.76 \\
8 & Epicatechin & 8.53 & 5.64 & 0.66 \\
9 & (-)-Epicatechin gallate & 0.11 & 0.03 & 0.31 \\
\hline \multicolumn{5}{c}{}
\end{tabular}

In this study, we first observed the anticancer effect of $70 \%$ ethanolic extract of SC and its constituents in two human breast cancer cell lines including the triple-negative MDA-MB-231 cells and the estrogen-receptor-positive MCF-7 cells. As shown in Figure 3, Gallic acid (GA) showed the strongest cytotoxic effect in MCF-7 cells of the tested compounds. Treatment with $100 \mu \mathrm{M}$ GA decreased cell viability to $29.33 \% \pm 1.41 \%(n=5, p=0.05)$, whereas exposure to $100 \mu \mathrm{M}(-)$-gallocatechin, $100 \mu \mathrm{g} / \mathrm{mL}$ $70 \%$ ethanol extract of SC, and $100 \mu \mathrm{M}(-)$-epicatechin gallate reduced the viability of MCF-7 cells to $52.88 \% \pm 6.71 \%(n=5, p=0.05), 67.01 \% \pm 2.35 \%(n=5, p=0.05)$, and $75.27 \% \pm 1.33 \%(n=5$, $p=0.05)$, respectively. The 3,4-Dihydroxybenzoic acid, procyanidin B1, 3,4-dihydroxybenzaldehyde, catechin, procyanidin B2, and epicatechin did not induce MCF-7 cell death. Cisplatin was analyzed as a reference drug [32] and decreased the viability of cells to $54.79 \% \pm 1.61 \%(n=5, p=0.05)$ at 
$100 \mu \mathrm{M}$. Moreover, the previous reports indicated that the phenolic compounds including catechins and procyanidins enhanced cytotoxicity of anticancer drugs (cisplatin and doxorubicin) in various cancer cell lines [33-35]. Thus, we continuously studied the cytotoxic effects of combination between GA (the strongest anti-cancer compound among tested samples) with 8 remaining phenolic compounds at $50 \mu \mathrm{M}$ in MCF-7 cells. As shown in Figure 4, GA did not show any synergistic anticancer effect with 8 studied compounds.

SC

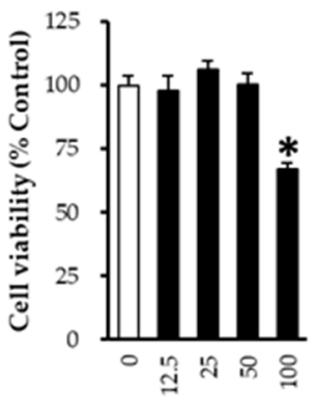

Concentration $(\mu \mathrm{g} / \mathrm{mL})$
1

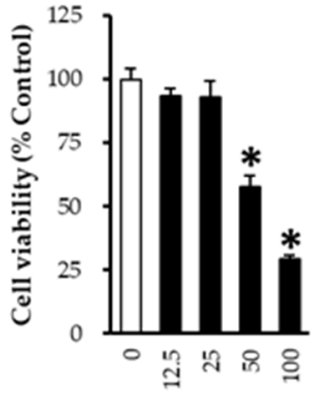

Concentration $(\mu \mathrm{M})$
2

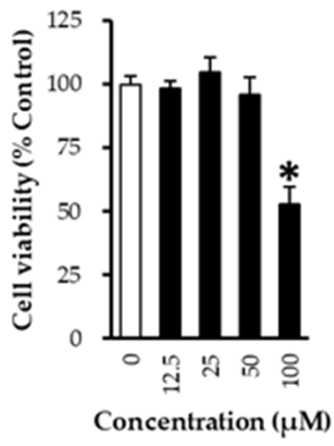

3

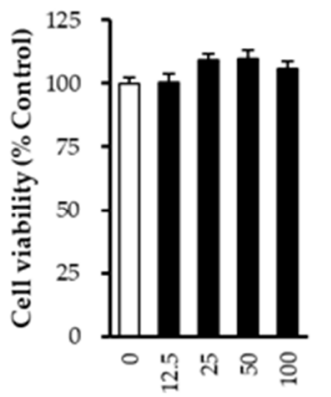

Concentration $(\mu \mathrm{M})$

4

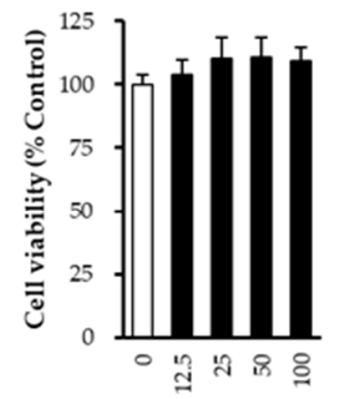

Concentration $(\mu \mathrm{M})$

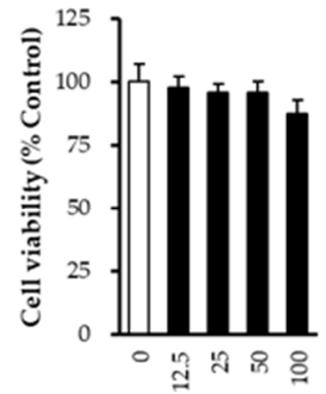

Concentration $(\mu \mathrm{M})$

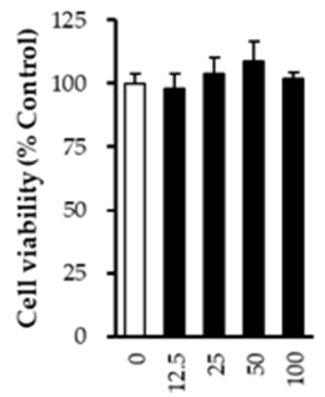

Concentration $(\mu \mathrm{M})$
7

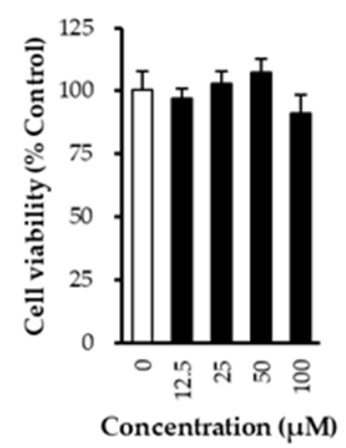

8

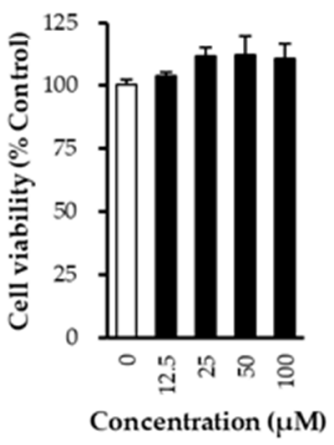

9

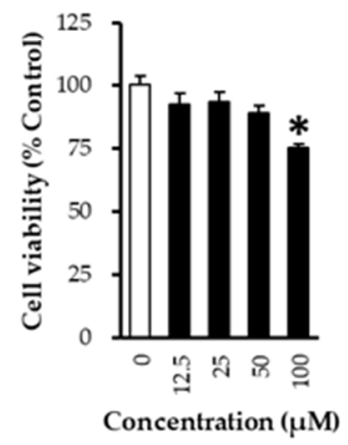

Cisplatin

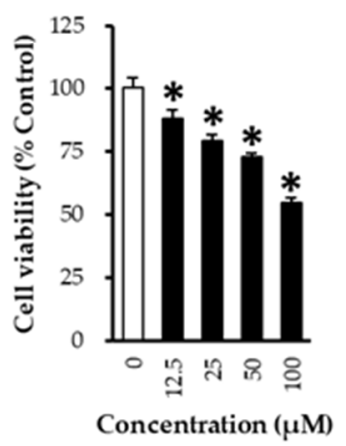

Figure 3. The cytotoxic effects of the 70\% ethanol extract of Spatholobi Caulis (SC), gallic acid (1), (-)-gallocatechin (2), 3,4-dihydroxybenzoic acid (3), procyanidin B1 (4), 3,4-dihydroxybenzaldehyde (5), catechin (6), procyanidin B2 (7), epicatechin (8), (-)-epicatechin gallate (9), and cisplatin (reference drug) in MCF-7 cells. The cells were treated with the sample for $24 \mathrm{~h}$, and cell survival was detected using the Ez-Cytox cell viability assay kit $(n=5)$. Data are presented as the mean \pm SD. ${ }^{*} p<0.05$ compared to the $0 \mu \mathrm{M}$ group. 


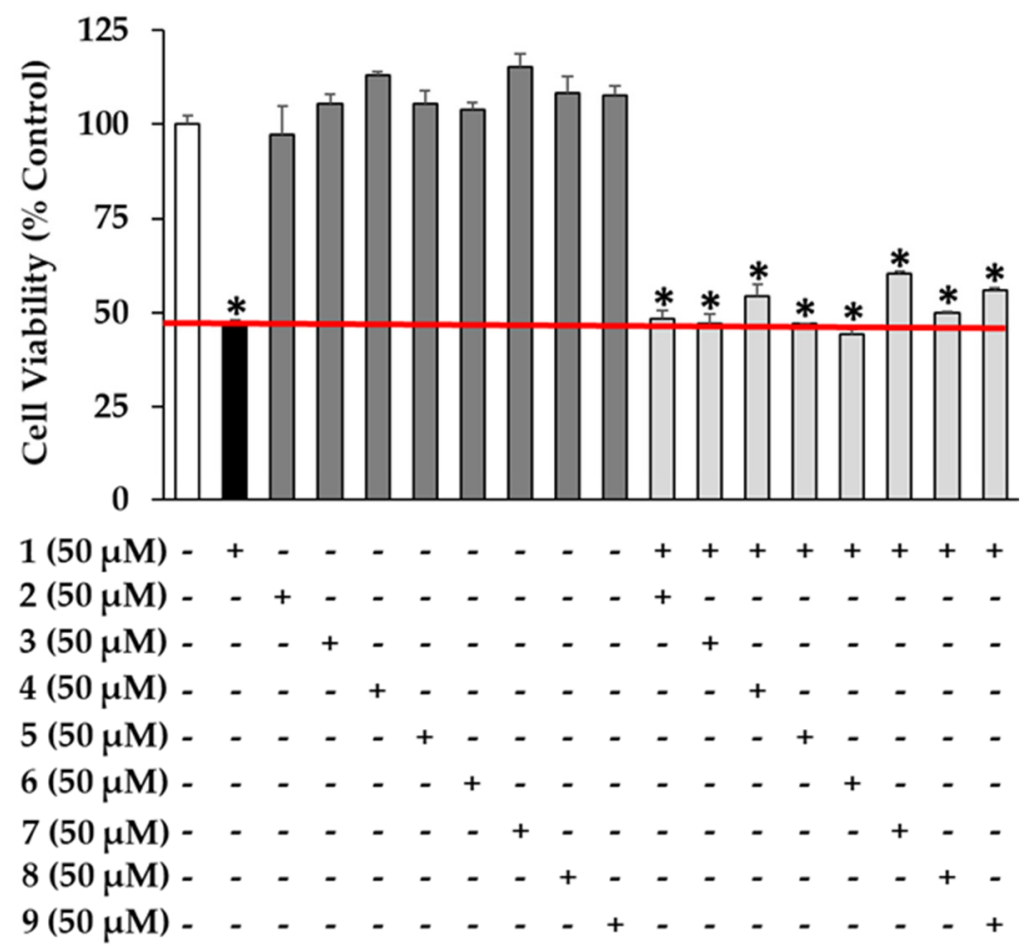

Figure 4. The cytotoxic effects of combination between gallic acid (1) and (-)-gallocatechin (2), 3,4-dihydroxybenzoic acid (3), procyanidin B1 (4), 3,4-dihydroxybenzaldehyde (5), catechin (6), procyanidin B2 (7), epicatechin (8), and (-)-epicatechin gallate (9) at $50 \mu \mathrm{M}$ in MCF-7 cells. The cells were treated with the sample for $24 \mathrm{~h}$, and cell survival was detected using the Ez-Cytox cell viability assay kit $(n=3)$. Data are presented as the mean \pm SD. ${ }^{*} p<0.05$ compared with the non-treated group. White bar: non-treated group; black bar: group was treated with $50 \mu \mathrm{M}$ gallic acid (1); dark gray bars: groups were single treated with 8 phenolic compounds (2-9) at $50 \mu \mathrm{M}$; and light gray bars: groups were co-treated gallic acid (1) with each phenolic compound (2-9) at $50 \mu \mathrm{M}$.

In term of MDA-MB-231 cells, only 70\% ethanol extract of SC significant decreased the viability of cell to $64.26 \% \pm 0.90 \%(n=5, p=0.05)$ at $100 \mu \mathrm{g} / \mathrm{mL}$. The cytotoxicity could not be detected in cells treated with 9 compounds. The positive control cisplatin inhibited viability of MDA-MB-231 cells to $45.67 \% \pm 1.12 \%(n=5, p=0.05)$ at $100 \mu \mathrm{M}$ (Figure 5).

SC

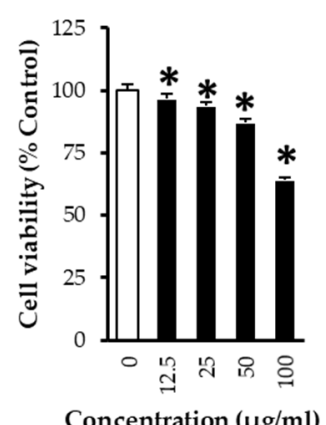

Concentration $(\mu \mathrm{g} / \mathrm{ml})$
1

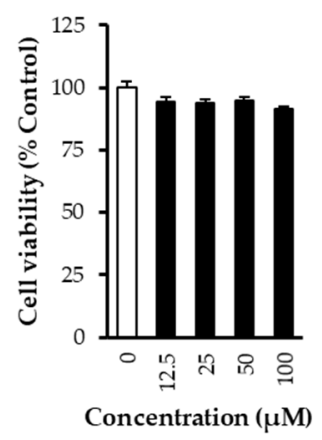

Figure 5. Cont.
2

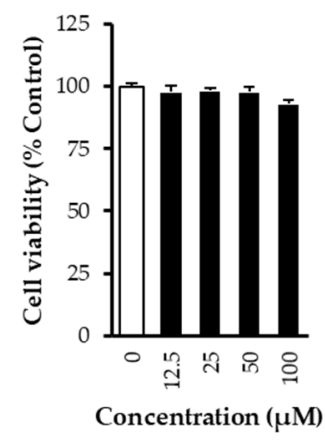


3

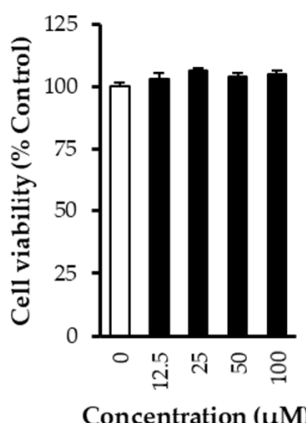

7

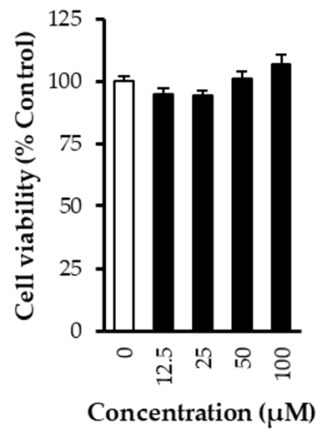

4

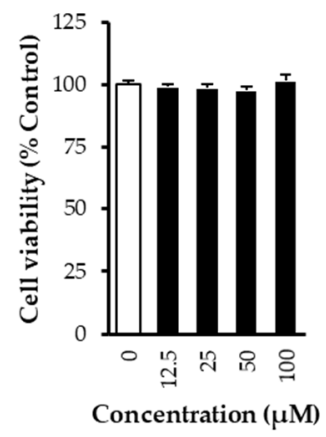

8

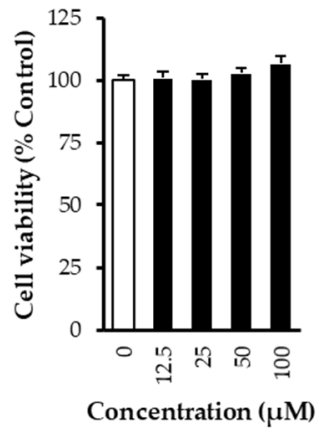

5

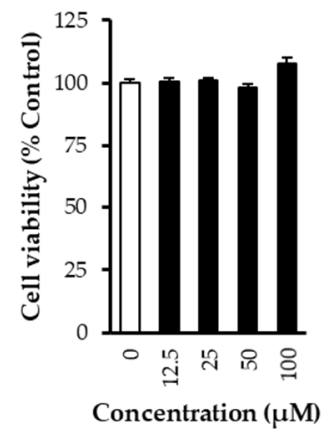

9

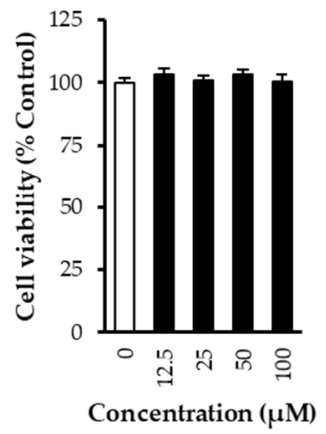

6

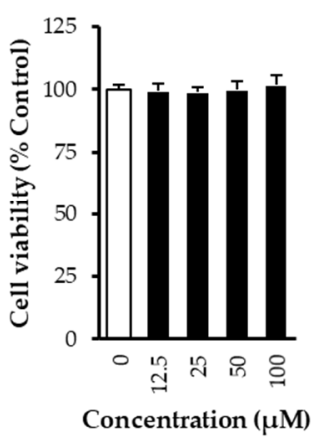

Cisplatin

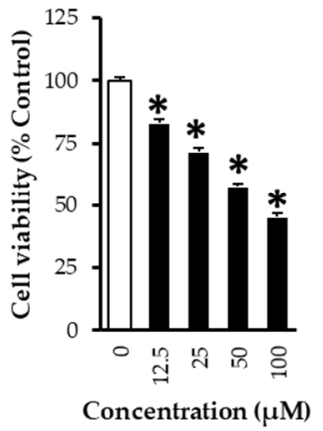

Figure 5. The cytotoxic effects of the 70\% ethanol extract of Spatholobi Caulis (SC), gallic acid (1), (-)-gallocatechin (2), 3,4-dihydroxybenzoic acid (3), procyanidin B1 (4), 3,4-dihydroxybenzaldehyde (5), catechin (6), procyanidin B2 (7), epicatechin (8), (-)-epicatechin gallate (9), and cisplatin (reference drug) in MDA-MB-231 cells. The cells were treated with the sample for $24 \mathrm{~h}$, and cell survival was detected using the Ez-Cytox cell viability assay kit $(n=5)$. Data are presented as the mean \pm SD. * $p<0.05$ compared to control group.

Based on these data, the cytotoxicity of GA in estrogen-receptor-positive MCF-7 cells is the most potential to extend anticancer mechanism study. In addition, GA did not affect the viability of human dermal fibroblast cells, which is control normal cells (Supplementary Material Figure S1).

Avoidance of programmed cell death is one of the six hallmarks of cancer that results in unregulated cell growth and tumor formation [36]. Thus, activation of the cell's inherent death mechanisms, such as apoptosis, is one method of cancer treatment, and aims to regain control of cell death or block uncontrolled cell proliferation. A recent review of anticancer therapy based on apoptosis targets showed that natural phytochemicals exerted their anticancer effects through the induction of programmed cell death [37].

The early apoptotic process includes several morphological changes, such as cell shrinkage, pyknosis, or plasma membrane blebbing. Chromatin condensation is the primary cause of pyknosis and is an important predictor of apoptosis, distinguishing it from necrosis [38]. Thus, the MCF-7 cells were stained with Hoechst 33,528 to assess effect of GA in inducing nuclear condensation. As shown in Figure 6A, treatment with GA increased chromatin condensation in a dose-dependent manner. The quantitative data analyzed from the fluorescence images indicated that the percentage of nuclear abnormalities increased to $59.36 \pm 3.60 \%$ in cells treated with $100 \mu \mathrm{M}$ GA compared to $0 \mu \mathrm{M}$ group $(n=2, p=0.05)$ (Figure 6B). 
A) $\mathrm{GA}(\mu \mathrm{M})$

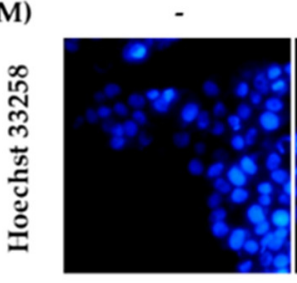

C) GA $(\mu \mathrm{M})$

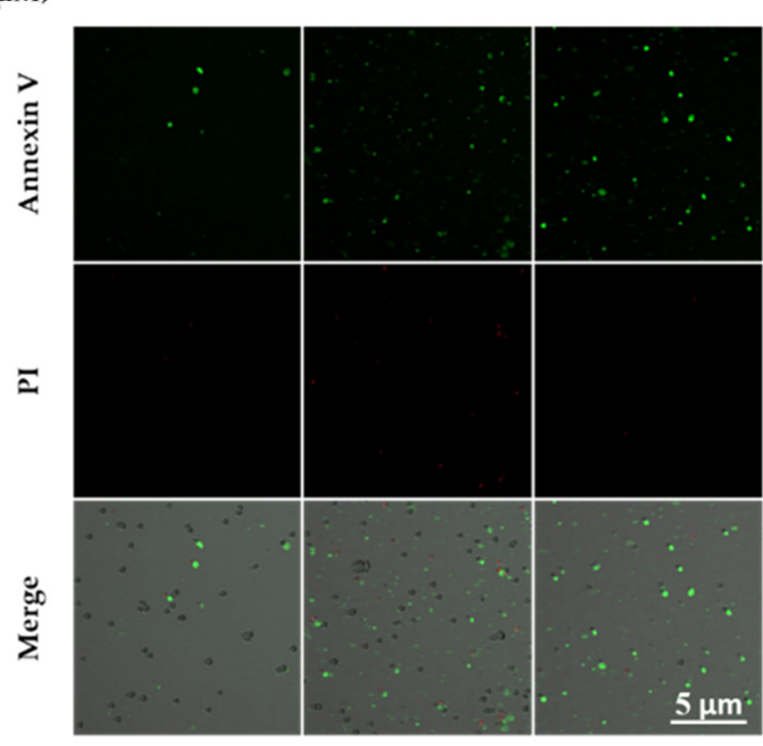

100

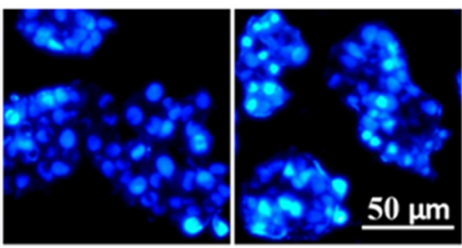

100

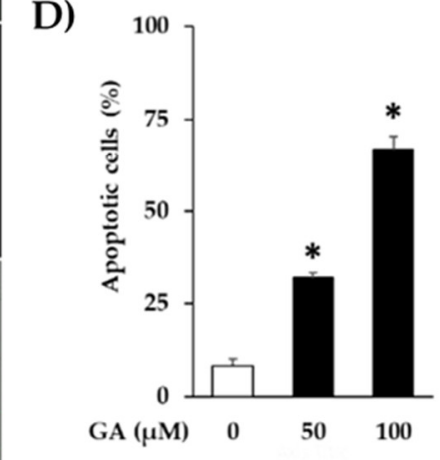

Figure 6. Apoptosis-inducing effect of gallic acid (GA) on MCF-7 cells. (A) The cells were exposed to the indicated doses of GA for $12 \mathrm{~h}$ and stained with Hoechst 33258. Fluorescent images were captured using a fluorescent microscope. (B) The bat chart depicts the proportion of nuclear abnormalities obtained from the fluorescence images $(n=2)$. (C) MCF-7 cells were treated with specific doses of GA for $12 \mathrm{~h}$ and dual stained with PI and annexin V to detect dead and apoptotic cells using the Tali ${ }^{\circledR}$ Image-Based Cytometer. (D) The bar graph describes the portion of annexin V stained cells indicating for cells undergoing apoptosis $(n=2)$. Data are presented as the mean \pm SD. ${ }^{*} p<0.05$ compared to the non-treated group.

In addition, we further confirmed effect of GA in inducing apoptotic MCF-7 cell death using Tali assay to quantify necrotic and apoptotic cells. From Figure $6 C$, we can see that GA increased the number of apoptotic cells (annexin $\mathrm{V}$ stained cells) in a concentration-dependent manner compared to non-treated cells. Moreover, the quantitative results showed that treatment with GA lifted the percentage of apoptotic cells to $32.14 \pm 1.12 \%$ and $66.80 \pm 3.54 \%$ at 50 and $100 \mu \mathrm{M}$ respectively $(n=2, p=0.05)$ (Figure 6D). Based on chromatin staining and quantitative apoptotic cell data, GA initially expressed the effect on promoting apoptosis in MCF-7 cells. Subsequently, we investigated the interaction between GA and proteins-modulated apoptosis to elucidate the mechanism-induced MCF-7 cell death.

In apoptosis, caspase proteins induce internal breakdown of cells. These caspases are activated through two distinct pathways, intrinsic and extrinsic. The intrinsic (or mitochondrial) pathway is triggered by intracellular signals, such as damaged DNA, growth factor deprivation, or surplus $\mathrm{Ca}^{2+}$, and is regulated by anti- and pro-apoptotic Bcl-2 protein family members (e.g., Bax/Bcl-2) in the mitochondria [37]. Bcl-2 prevents apoptosis by blocking mitochondrial cytochrome $\mathrm{c}$ release, whereas Bax increases the permeability of the mitochondrial membrane and induces the release of cytochrome c, which leads to caspase-9 activation [39]. In contrast with the intrinsic pathway, the extrinsic pathway is activated by extracellular cell death signals, known as "death ligands". These death ligands bind to 
death receptors, such as TNFR1, FAS, or DRS, thereby inducing the activation of caspase-3, $-6,-7$, and -8 , cleaving the cytoskeletal proteins and causing cell death [37].

As a famous anticancer phytochemistry, the apoptotic mechanism of GA has been widely investigated in various malignant cell lines [40-42]. For instance, Sun and colleagues (2016) indicated that GA induced apoptosis in SMMC-7721 human hepatocellular carcinoma cells via mitochondrial pathway by activation of caspase 3 and 9, decrease of Bcl-2 expression and increase of Bax level [42]. In addition, treatment with GA also induced apoptotic AGS human gastric adenocarcinoma cell death through extrinsic pathway mediated by caspase 8 activation [43]. However, our MCF-7 cell line obtained from ATCC does not express caspase 3 [44] (Supplementary Material Figure S2). Thus, we chose caspase 7 as an alternative apoptotic effector caspase.

As shown in Figure 7, GA activated the apoptotic process through both intrinsic and extrinsic pathways. In detail, treatment with GA increased the expression of the pro-apoptotic protein Bax and cleaved caspase-7, -8 , and -9 , but decreased the expression of the anti-apoptotic protein Bcl-2. In addition, GA reduced expression of PARP involved in maintaining cell viability and increased tumor protein 553 level, which is an indicator of DNA damage.

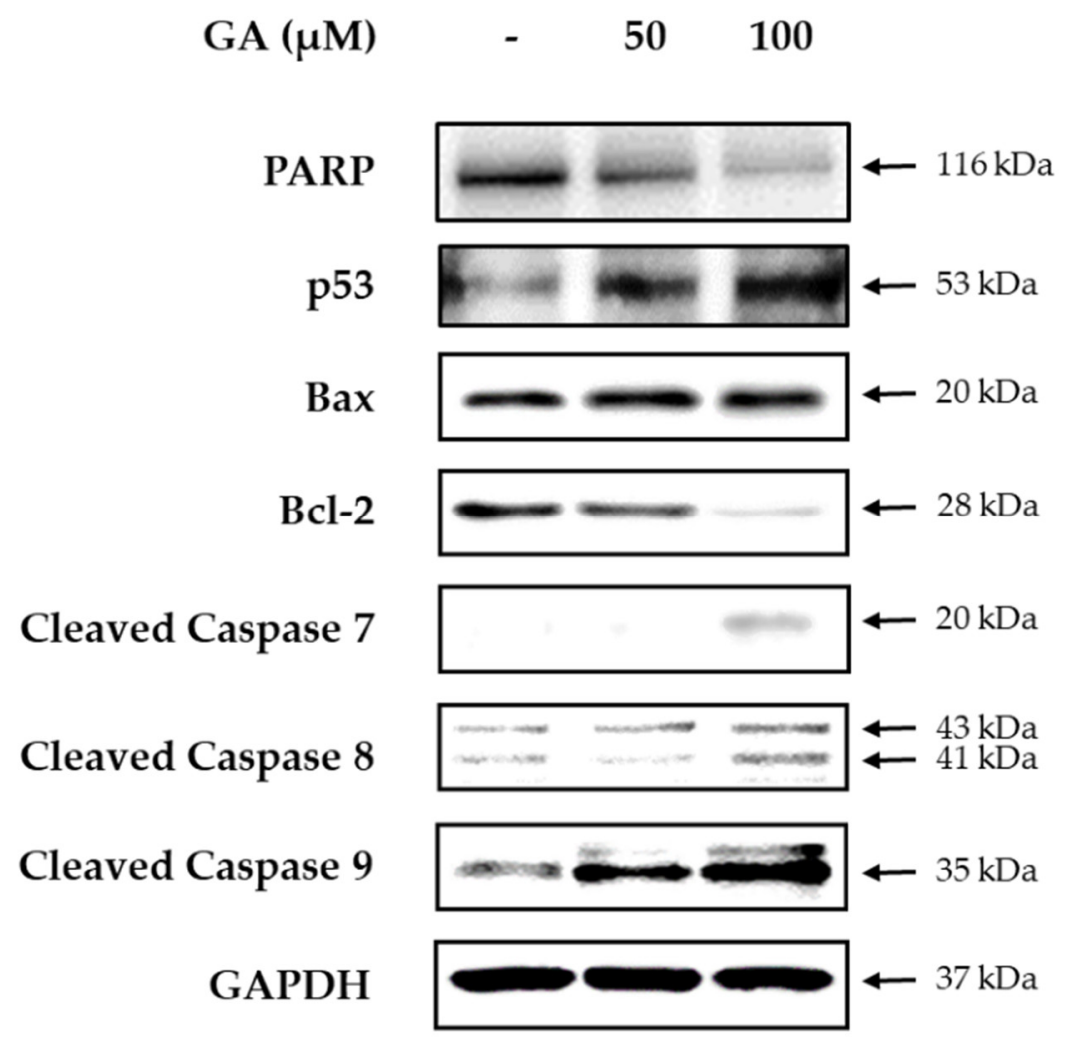

Figure 7. Effect of gallic acid (GA) on expression of protein-mediated apoptosis in MCF-7 cells. The cells were treated with specific doses of GA for $24 \mathrm{~h}$, and the protein expression was determined by western blotting $(n=2)$.

Furthermore, we conducted a network pharmacological analysis to elucidate the systems-level mechanism of GA. We identified 16 target genes of GA from STITCH, a protein-chemical interaction database. These targets are either curated from literature or predicted by machine learning algorithms. To test whether these targets were significantly associated with the pathways in breast cancer and its related pathways, GSEA was performed based on KEGG 29. Breast cancer-related pathways, obtained from KEGG, were: breast cancer, estrogen signaling pathway, MAPK (mitogen-activated protein kinase) signaling pathway, PI3K (phosphoinositide 3-kinase)-Akt signaling pathway, Notch signaling pathway, Wnt signaling pathway, p53 signaling pathway, cell cycle, and homologous recombination. 
Among those pathways, p53, MAPK, estrogen, and Wnt signaling pathway showed enrichment (adjusted $p$-values $<0.05$ ) and high combined scores (Table 3). The pathway of breast cancer itself did not show significant association with targets of GA. This suggest that promising but undiscovered pathways explaining the anti-breast cancer effect of GA may exist. One of the potential mechanisms of GA in breast cancer was summarized focusing on p53 signaling pathway, using KEGG mapper (Figure 8). In the p53 signaling pathway, ATM and CASP3, a couple of targets of GA, are related to Bax and Bcl-2. It suggests the possibility that GA activates ATM resulting in changing ratio of Bcl-2 and Bax and it accelerates apoptosis of MCF-7 with synergistic effects of GA on CASP3.

Table 3. Enrichment analysis of relevant breast cancer pathways by the targets of gallic acid (GA).

\begin{tabular}{cccccc}
\hline Term & Overlap & $\begin{array}{c}\text { Adjusted } \\
p \text {-Value }\end{array}$ & $\begin{array}{c}\text { Odds } \\
\text { Ratio }\end{array}$ & $\begin{array}{c}\text { Combined } \\
\text { Score }\end{array}$ & Genes \\
\hline p53 signaling pathway *** & $3 / 72$ & 0.00053 & 52.08 & 553.55 & CASP3; SERPINE1; ATM \\
MAPK signaling pathway ** & $4 / 295$ & 0.0019 & 16.95 & 161.35 & JUN; CHUK; CASP3; PRKCA \\
Estrogen signaling pathway ** & $3 / 137$ & 0.0022 & 27.37 & 238.41 & JUN; MMP2; MMP9 \\
Wnt signaling pathway * & $2 / 158$ & 0.034 & 15.82 & 78.69 & JUN; PRKCA \\
PI3K-Akt signaling pathway & $2 / 354$ & 0.13 & 7.06 & 24.35 & CHUK; PRKCA \\
Homologous recombination & $1 / 41$ & 0.13 & 30.49 & 104.64 & ATM \\
Cell cycle & $1 / 124$ & 0.24 & 10.08 & 23.76 & ATM \\
Breast cancer & $1 / 147$ & 0.26 & 8.50 & 18.66 & JUN \\
\hline
\end{tabular}

${ }^{*}$ Adjusted $p$-value $<0.05,{ }^{* *}$ adjusted $p$-value $<0.01,{ }^{* * *}$ adjusted $p$-value $<0.001$. MAPK, mitogen-activated protein kinase; PI3K, phosphoinositide 3-kinase.

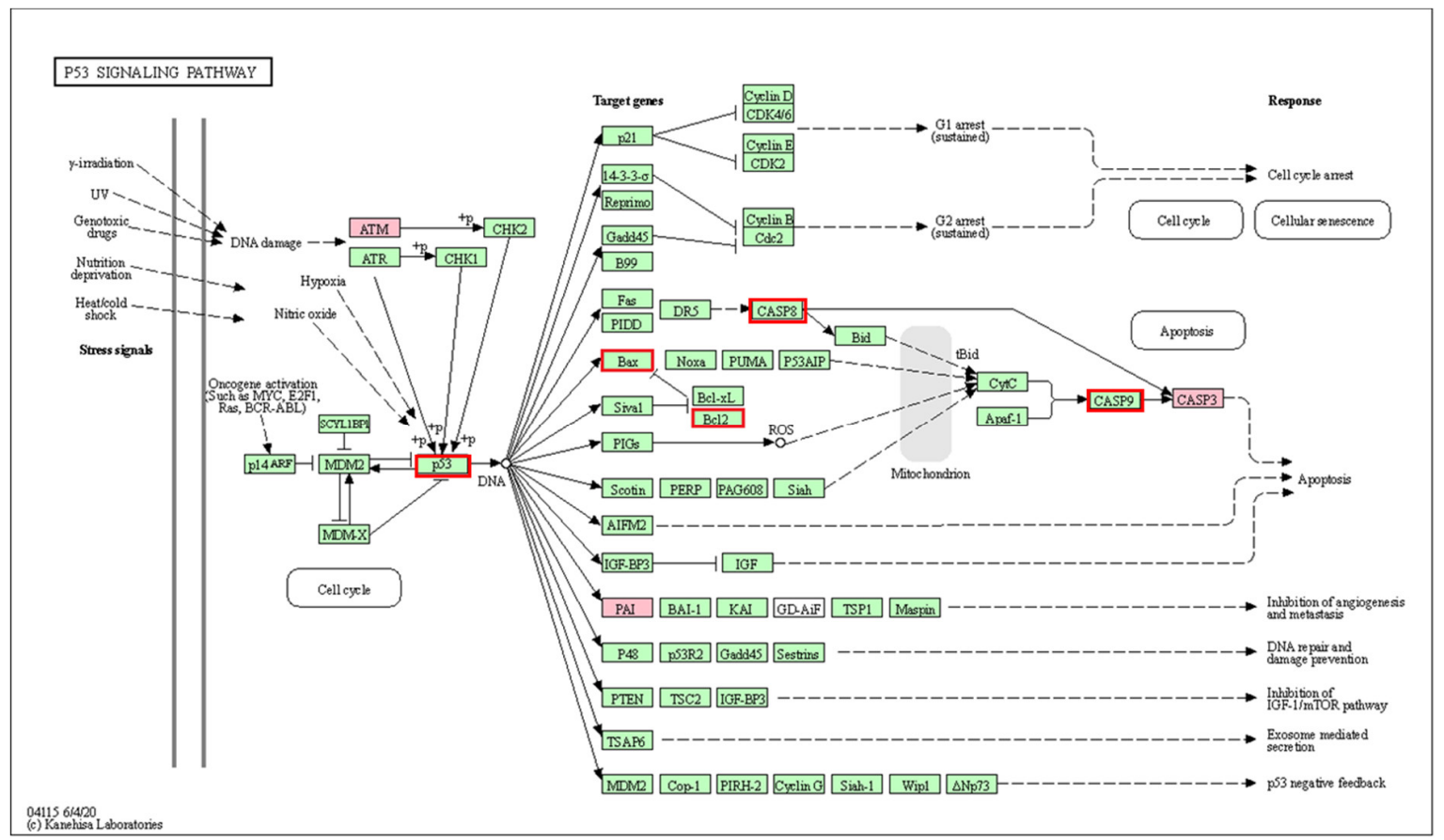

Figure 8. p53 signaling pathway (hsa04115) and gallic acid (GA)-related genes. The Kyoto Encyclopedia of Genes and Genomes (KEGG) mapper was applied to build pathway maps. White round squares and green boxes depict pathways and genes, respectively. Pink-colored boxes and red-rimmed boxes represent predicted targets of GA and validated genes in western blotting analysis, respectively.

To elucidate compound-target interactions, we constructed and visualized the compound-target network between GA and its target genes (Figure 9). There were 3, 4, 3, and 2 related targets for the p53 signaling pathway, MAPK signaling pathway, estrogen signaling pathway, and Wnt signaling pathway, respectively. Especially, CASP3, JUN and PRKCA involves in multiple pathways related with 
breast cancer. These results imply that the effect of GA is mediated by the simultaneous modulation of multiple targets related to multiple pathways related to breast cancer.

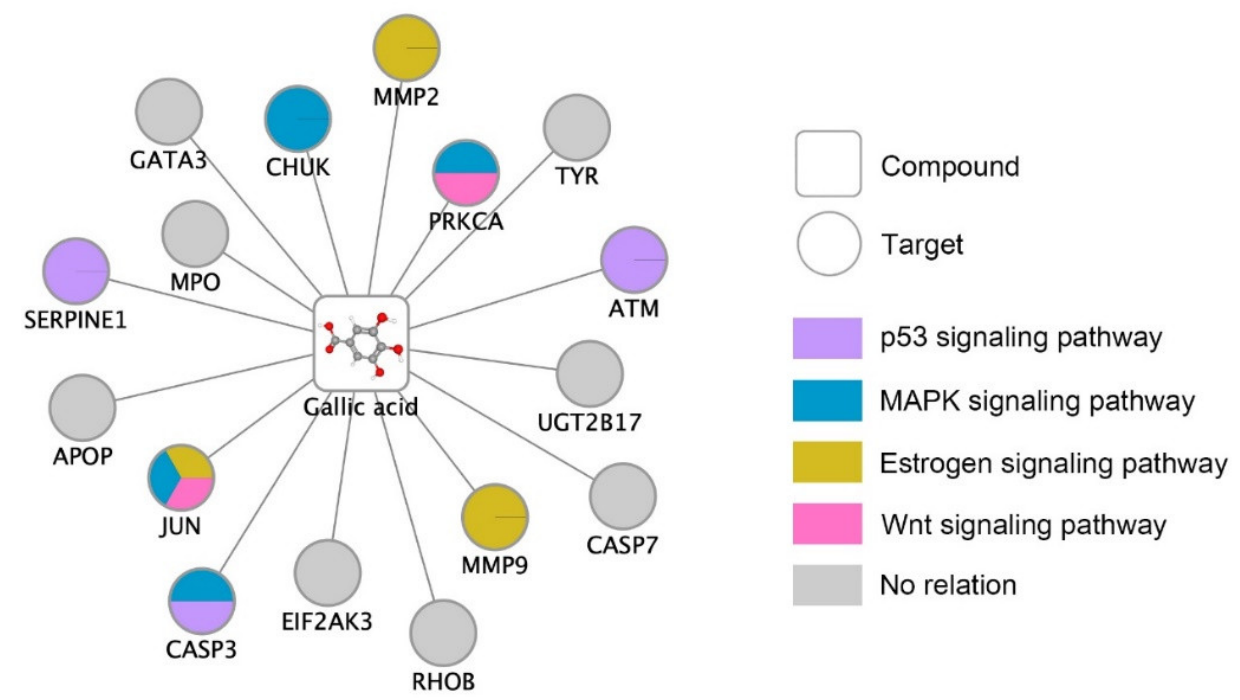

Figure 9. Compound-target network of gallic acid (GA). An edge between a compound and a target indicates the compound interacts with the target. The colors of target nodes represent which pathways the targets involve in. MAPK, mitogen-activated protein kinase.

In addition, although caspase 3 could not be detected in this study, the data of network pharmacology predicted that target of GA-induced human breast cancer cell death may involve in caspase 3 associated with p53 signaling pathway with high accordance rate ( $p$-value $<0.001)$. In addition, target of GA also had high relation with estrogen signaling pathway ( $p$-value $<0.01$ ), which supported to explain why GA expressed strong cytotoxicity on estrogen-receptor-positive MCF-7 cells while its anticancer effect could not be detected on triple-negative breast cancer MDA-MB-231 cells in our present study.

In conclusion, nine constituent compounds (gallic acid, (-)-gallocatechin, 3,4-dihydroxybenzoic acid, procyanidin B1, 3,4-dihydroxybenzaldehyde, catechin, procyanidin B2, epicatechin, and (-)-epicatechin gallate) found in SC were analyzed simultaneously, and their anticancer effects on MCF-7 and MDA-MB-231 human breast cancer cells were assessed. The experiment data pointed out that GA showed the strongest cytotoxic effect on MCF-7 cells among tested compounds whilst most of samples did not express inhibitory effect on viability of MDA-MB-231 cells, except for $70 \%$ ethyl alcohol extract of SC. With regard to the mechanism, GA promoted apoptotic MCF-7 cell death via both the intrinsic and extrinsic pathways by enhancing the expression of the pro-apoptotic protein Bax, p53 and cleaved caspase-7, -8 , and -9 , but reducing the expression of the anti-apoptotic protein Bcl-2 and PARP. In addition, the results obtained from network pharmacology showed that the p53, MAPK, estrogen, and Wnt signaling pathway are the most potential pathways linked with targets of GA. Based on these results, we suggest that GA is the active component of SC, which is potential for applying to breast malignancy chemotherapy.

Supplementary Materials: The following are available online at http://www.mdpi.com/2227-9717/8/9/1193/s1, Figure S1: The cytotoxic effects of the 70\% ethanol extract of Spatholobi Caulis (SC), gallic acid (1), (-)-gallocatechin (2), 3,4-dihydroxybenzoic acid (3), procyanidin B1 (4), 3,4-dihydroxybenzaldehyde (5), catechin (6), procyanidin B2 (7), epicatechin (8), and (-)-epicatechin gallate (9) in human dermal fibroblast (HDF) cells. Figure S2: Effect of $70 \%$ ethanol extract of gallic acid (GA) on expression of cleaved caspase 3 in MCF-7 cells.

Author Contributions: C.-S.S. and Y.-K.C. conceived and designed the experiments; H.M.P. and H.L. performed cell experiments and western blotting. S.L., K.S.K., D.J., C.-E.K. and H.L. analyzed the data; C.-S.S. and Y.-K.C. reviewed and edited the original manuscript. All authors have read and approved the final manuscript. 
Funding: The present study was also supported by the Basic Science Research Program through the National Research Foundation of Korea (NRF) (2019R1F1A1059173).

Acknowledgments: We thank Jung-Eun Lee of Korea Institutes of Oriental Medicine (Daejeon, Korea) for helping to identify gallic acid in the sample using LC-MS.

Conflicts of Interest: The authors declare no conflict of interest.

\section{References}

1. Siegel, R.L.; Miller, K.D.; Jemal, A. Cancer statistics, 2019. CA Cancer J.Clin. 2019, 69, 7-34. [CrossRef] [PubMed]

2. Wörmann, B. Breast cancer: Basics, screening, diagnostics and treatment. Med. Mon. Pharm. 2017, 40, 55-64.

3. Chang-Claude, J.; Popanda, O.; Tan, X.-L.; Kropp, S.; Helmbold, I.; von Fournier, D.; Haase, W.; Sautter-Bihl, M.L.; Wenz, F.; Schmezer, P. Association between polymorphisms in the DNA repair genes, XRCC1, APE1, and XPD and acute side effects of radiotherapy in breast cancer patients. Clin. Cancer Res. 2005, 11, 4802-4809. [CrossRef]

4. Partridge, A.H.; Burstein, H.J.; Winer, E.P. Side effects of chemotherapy and combined chemohormonal therapy in women with early-stage breast cancer. JNCI Monogr. 2001, 2001, 135-142. [CrossRef] [PubMed]

5. Khan, T.; Ali, M.; Khan, A.; Nisar, P.; Jan, S.A.; Afridi, S.; Shinwari, Z.K. Anticancer plants: A Review of the active phytochemicals, applications in animal models, and regulatory aspects. Biomolecules 2020, 10, 47. [CrossRef]

6. Majolo, F.; Delwing, L.K.D.O.B.; Marmitt, D.J.; Bustamante-Filho, I.C.; Goettert, M.I. Medicinal plants and bioactive natural compounds for cancer treatment: Important advances for drug discovery. Phytochem. Lett. 2019, 31, 196-207. [CrossRef]

7. Olaku, O.; White, J.D. Herbal therapy use by cancer patients: A literature review on case reports. Eur. J. Cancer 2011, 47, 508-514. [CrossRef]

8. Kamei, T.; Kumano, H.; Iwata, K.; Nariai, Y.; Matsumoto, T. The effect of a traditional Chinese prescription for a case of lung carcinoma. J. Altern. Complement. Med. 2000, 6, 557-559. [CrossRef]

9. Sun, L.-R.; Zhou, W.; Zhang, H.-M.; Guo, Q.-S.; Yang, W.; Li, B.-J.; Sun, Z.-H.; Gao, S.-H.; Cui, R.-J. Modulation of multiple signaling pathways of the plant-derived natural products in cancer. Front. Oncol. 2019, 9, 9. [CrossRef]

10. Millimouno, F.M.; Dong, J.; Yang, L.; Li, J.; Li, X. Targeting apoptosis pathways in cancer and perspectives with natural compounds from mother nature. Cancer Prev. Res. 2014, 7, 1081-1107. [CrossRef]

11. Im, N.-K.; Lee, S.-G.; Lee, D.-S.; Park, P.-H.; Lee, I.-S.; Jeong, G.-S. Spatholobus suberectus inhibits osteoclastogenesis and stimulates chondrogenesis. Am. J. Chin. Med. 2014, 42, 1123-1138. [CrossRef] [PubMed]

12. Li, R.W.; Lin, G.D.; Myers, S.P.; Leach, D.N. Anti-inflammatory activity of Chinese medicinal vine plants. J. Ethnopharmacol. 2003, 85, 61-67. [CrossRef]

13. Pang, J.; Guo, J.-P.; Jin, M.; Chen, Z.-Q.; Wang, X.-W.; Li, J.-W. Antiviral effects of aqueous extract from Spatholobus suberectus Dunn. against coxsackievirus B3 in mice. Chin. J. Integr. Med. 2011, 17, 764-769. [CrossRef] [PubMed]

14. Park, H.R.; Lee, H.; Lee, J.-J.; Yim, N.-H.; Gu, M.-J.; Ma, J.Y. Protective effects of spatholobi caulis extract on neuronal damage and focal ischemic stroke/reperfusion injury. Mol. Neurobiol. 2018, 55, 4650-4666. [CrossRef] [PubMed]

15. Su, E.; Fang, Y.; Chen, H. Clinical observation of treating 62 patients with severe aplastic anemia failing in immunosuppressive therapy by integrative medicine. Chin. J. Integr. Tradit. West. Med. 2012, 32, 1616-1620.

16. Ha, E.-S.; Lee, E.-O.; Yoon, T.-J.; Kim, J.-H.; Park, J.-O.; Lim, N.-C.; Jung, S.-K.; Yoon, B.-S.; Kim, S.-H. Methylene chloride fraction of Spatholobi Caulis induces apoptosis via caspase dependent pathway in U937 cells. Biol. Pharm. Bull. 2004, 27, 1348-1352. [CrossRef]

17. Liu, B.; Liu, J.; Chen, J.; Zhu, D.; Zhou, H.; Wang, X. Study on anticancer activity of caulis spatholobi extract on human osteosarcoma saos-2 cells. Afr. J. Tradit. Complement. Altern. Med. 2013, 10, 256-260. [CrossRef]

18. Sun, L.; Li, Q.; Guo, Y.; Yang, Q.; Yin, J.; Ran, Q.; Liu, L.; Zhao, Z.; Wang, Y.; Li, Y. Extract of Caulis Spatholobi, a novel platelet inhibitor, efficiently suppresses metastasis of colorectal cancer by targeting tumor cell-induced platelet aggregation. Biomed. Pharmacother. 2020, 123, 109718. [CrossRef] 
19. Wang, N.; Wang, J.; Meng, X.; Bao, Y.; Wang, S.; Li, T. 3D microfluidic in vitro model and bioinformatics integration to study the effects of Spatholobi Caulis tannin in cervical cancer. Sci. Rep. 2018, 8, 1-11. [CrossRef]

20. Wang, N.; Wang, J.; Meng, X.; Li, T.; Wang, S.; Bao, Y. The pharmacological effects of spatholobi caulis tannin in cervical cancer and its precise therapeutic effect on related circRNA. Mol. Ther. Oncolytics 2019, 14, 121-129. [CrossRef]

21. Huang, Y.; Chen, L.; Feng, L.; Guo, F.; Li, Y. Characterization of total phenolic constituents from the stems of Spatholobus suberectus using LC-DAD-MSn and their inhibitory effect on human neutrophil elastase activity. Molecules 2013, 18, 7549-7556. [CrossRef] [PubMed]

22. Zhang, Y.; Guo, L.; Duan, L.; Dong, X.; Zhou, P.; Liu, E.-H.; Li, P. Simultaneous determination of 16 phenolic constituents in Spatholobi Caulis by high performance liquid chromatography/electrospray ionization triple quadrupole mass spectrometry. J. Pharm. Biomed. Anal. 2015, 102, 110-118. [CrossRef] [PubMed]

23. Lu, D.; He, H.; Wu, B.; Yao, S. Cytotoxic Effect on Cancer Cells and Structural Identification of Phenols from Spatholobi Caulis by HPLC-ESI-MSn. Nat. Prod. Commun. 2009, 4. [CrossRef]

24. Baek, S.J.; Kim, J.-S.; Jackson, F.R.; Eling, T.E.; McEntee, M.F.; Lee, S.-H. Epicatechin gallate-induced expression of NAG-1 is associated with growth inhibition and apoptosis in colon cancer cells. Carcinogenesis 2004, 25, 2425-2432. [CrossRef]

25. Lim, Y.C.; Lee, S.-H.; Song, M.H.; Yamaguchi, K.; Yoon, J.-H.; Choi, E.C.; Baek, S.J. Growth inhibition and apoptosis by (-)-epicatechin gallate are mediated by cyclin D1 suppression in head and neck squamous carcinoma cells. Eur. J. Cancer 2006, 42, 3260-3266. [CrossRef]

26. Chen, H.-M.; Wu, Y.-C.; Chia, Y.-C.; Chang, F.-R.; Hsu, H.-K.; Hsieh, Y.-C.; Chen, C.-C.; Yuan, S.-S. Gallic acid, a major component of Toona sinensis leaf extracts, contains a ROS-mediated anti-cancer activity in human prostate cancer cells. Cancer Lett. 2009, 286, 161-171. [CrossRef] [PubMed]

27. Ohno, Y.; Fukuda, K.; Takemura, G.; Toyota, M.; Watanabe, M.; Yasuda, N.; Xinbin, Q.; Maruyama, R.; Akao, S.; Gotou, K. Induction of apoptosis by gallic acid in lung cancer cells. Anticancer Drugs 1999, 10, 845-851. [CrossRef]

28. Xia, T.; Zhang, J.; Zhou, C.; Li, Y.; Duan, W.; Zhang, B.; Wang, M.; Fang, J. 20 (S)-Ginsenoside Rh2 displays efficacy against T-cell acute lymphoblastic leukemia through the PI3K/Akt/mTOR signal pathway. J. Ginseng Res. 2019. [CrossRef]

29. Jang, M.G.; Ko, H.C.; Kim, S.J. Effect of sasa quelpaertensis Nakai extracts and its constituent p-coumaric acid on the apoptosis of human cancer cell lines. Nat. Prod. Sci. 2018, 24, 293-297. [CrossRef]

30. Kuhn, M.; Szklarczyk, D.; Pletscher-Frankild, S.; Blicher, T.H.; Von Mering, C.; Jensen, L.J.; Bork, P. STITCH 4: Integration of protein-chemical interactions with user data. Nucleic Acids Res. 2014, 42, D401-D407. [CrossRef]

31. Kuleshov, M.V.; Jones, M.R.; Rouillard, A.D.; Fernandez, N.F.; Duan, Q.; Wang, Z.; Koplev, S.; Jenkins, S.L.; Jagodnik, K.M.; Lachmann, A. Enrichr: A comprehensive gene set enrichment analysis web server 2016 update. Nucleic Acids Res. 2016, 44, W90-W97. [CrossRef] [PubMed]

32. Sledge, G.W., Jr.; Loehrer, P.J., Sr.; Roth, B.J.; Einhorn, L.H. Cisplatin as first-line therapy for metastatic breast cancer. J. Clin. Oncol. 1988, 6, 1811-1814. [CrossRef] [PubMed]

33. Fujiki, H.; Sueoka, E.; Watanabe, T.; Suganuma, M. Synergistic enhancement of anticancer effects on numerous human cancer cell lines treated with the combination of EGCG, other green tea catechins, and anticancer compounds. J. Cancer Res. Clin. Oncol. 2015, 141, 1511-1522. [CrossRef] [PubMed]

34. Ma, X.; Zheng, C.; Han, L.; Xie, B.; Jia, J.; Cao, Z.; Li, Y.; Chen, Y. Synergistic therapeutic actions of herbal ingredients and their mechanisms from molecular interaction and network perspectives. Drug Discov. Today 2009, 14, 579-588. [CrossRef] [PubMed]

35. Yu, R.-J.; Liu, H.-B.; Yu, Y.; Liang, L.; Xu, R.; Liang, C.; Tang, J.-S.; Yao, X.-S. Anticancer activities of proanthocyanidins from the plant Urceola huaitingii and their synergistic effects in combination with chemotherapeutics. Fitoterapia 2016, 112, 175-182. [CrossRef] [PubMed]

36. Hanahan, D.; Weinberg, R.A. The hallmarks of cancer. Cell 2000, 100, 57-70. [CrossRef]

37. Pfeffer, C.M.; Singh, A.T. Apoptosis: A target for anticancer therapy. Int. J. Mol. Sci. 2018, $19,448$.

38. Elmore, S. Apoptosis: A review of programmed cell death. Toxicol. Pathol. 2007, 35, 495-516. [CrossRef] 
39. Murphy, K.; Ranganathan, V.; Farnsworth, M.; Kavallaris, M.; Lock, R.B. Bcl-2 inhibits Bax translocation from cytosol to mitochondria during drug-induced apoptosis of human tumor cells. Cell Death Differ. 2000, 7, 102-111. [CrossRef]

40. Faried, A.; Kurnia, D.; Faried, L.; Usman, N.; Miyazaki, T.; Kato, H.; Kuwano, H. Anticancer effects of gallic acid isolated from Indonesian herbal medicine, Phaleria macrocarpa (Scheff.) Boerl, on human cancer cell lines. Int. J. Oncol. 2007, 30, 605-613. [CrossRef]

41. Lo, C.; Lai, T.-Y.; Yang, J.-H.; Yang, J.-S.; Ma, Y.-S.; Weng, S.-W.; Chen, Y.-Y.; Lin, J.-G.; Chung, J.-G. Gallic acid induces apoptosis in A375. S2 human melanoma cells through caspase-dependent and-independent pathways. Int. J. Oncol. 2010, 37, 377-385. [PubMed]

42. Sun, G.; Zhang, S.; Xie, Y.; Zhang, Z.; Zhao, W. Gallic acid as a selective anticancer agent that induces apoptosis in SMMC-7721 human hepatocellular carcinoma cells. Oncol. Lett. 2016, 11, 150-158. [CrossRef] [PubMed]

43. Tsai, C.-L.; Chiu, Y.-M.; Ho, T.-Y.; Hsieh, C.-T.; Shieh, D.-C.; Lee, Y.-J.; Tsay, G.J.; Wu, Y.-Y. Gallic acid induces apoptosis in human gastric adenocarcinoma cells. Anticancer Res. 2018, 38, 2057-2067. [PubMed]

44. Jänicke, R.U. MCF-7 breast carcinoma cells do not express caspase-3. Breast Cancer Res. Treat. 2009, 117, 219-221. [CrossRef]

(C) 2020 by the authors. Licensee MDPI, Basel, Switzerland. This article is an open access article distributed under the terms and conditions of the Creative Commons Attribution (CC BY) license (http://creativecommons.org/licenses/by/4.0/). 